\title{
Underwater optical environment in the coastal waters of British Columbia, Canada
}

\author{
Eduardo Loos ${ }^{a \star}$, Maycira Costa ${ }^{b}$, and Sophia Johannessen ${ }^{c}$ \\ ${ }^{a}$ ASL Environmental Sciences, 1-6703 Rajpur Place, Victoria, BC V8M 1Z5, Canada; ${ }^{b}$ Department of \\ Geography, University of Victoria, P.O. Box 1700, Victoria, BC V8W 2Y2, Canada; ' Institute of Ocean \\ Sciences, Fisheries and Oceans Canada, 9860 West Saanich Road, P.O. Box 6000, Sidney, BC V8L 4B2, \\ Canada \\ *eloos@aslenv.com
}

\begin{abstract}
We describe the underwater light field of the Strait of Georgia in spring and summer, using apparent optical properties (reflectance, attenuation coefficient of downwelling irradiance, the average cosine of downwelling irradiance, and the attenuation of scalar irradiance). Both the attenuation and reflectance of photosynthetically available radiation (PAR; 400-700 $\mathrm{nm}$ ) are highest in the turbid waters of the Fraser River plume, due to scattering by mainly inorganic particles and absorption by coloured dissolved organic matter, phytoplankton, and other organic particles. Light is most diffuse in the surface waters of the plume and least diffuse at depth and away from the plume. Throughout the Strait, blue and red wavelengths are attenuated most rapidly resulting in a green peak of reflectance, the portion of the electromagnetic spectrum that penetrates the most deeply. PAR is attenuated to $1 \%$ of its surface intensity within 6-22 $\mathrm{m}$ in the spring and $4-23 \mathrm{~m}$ in the summer. For red and blue light, the depth of $1 \%$ penetration is never deeper than $9 \mathrm{~m}$. All of the visible radiation, with the exception of some green light, is absorbed within the outflowing layer $(15-30 \mathrm{~m})$ that is exported from the Strait with the estuarine circulation. The rapid extinction of light helps to explain the very shallow distribution of phytoplankton.
\end{abstract}

Citation: Loos E, Costa M, and Johannessen S. 2017. Underwater optical environment in the coastal waters of British Columbia, Canada. FACETS 2: 872-891. doi: 10.11 39/facets-2017-0074

Editor: Nelson O'Driscoll

Received: June 19, 2017

Accepted: August 17, 2017

Published: November 14, 2017

Copyright: @ 2017 Loos et al. and Her Majesty the Queen in Right of Canada. This work is licensed under a Creative Commons Attribution 4.0 International License (CC BY 4.0), which permits unrestricted use, distribution, and reproduction in any medium, provided the original author(s) and source are credited.

Published by: Canadian Science Publishing

Key words: light, irradiance, apparent optical properties, reflectance, Strait of Georgia, British Columbia, Canada

\section{Introduction}

The Strait of Georgia (SoG), a highly productive, estuarine coastal sea off the west coast of Canada, supports several commercial fisheries, including that for the iconic sockeye salmon. Its productivity is governed by physical, chemical, and biological forcing, including the penetration of sunlight into the water column (Peña et al. 2016). The underwater light field is of fundamental importance to phytoplankton dynamics and ultimately to fisheries. In addition to the external forcing (length of day, sun angle, cloud cover, and surface-reflected light), the quantity and quality of the available light for photosynthesis depends on the attenuation processes, specifically on the scattering and absorption of light within the water column (Kirk 1994).

In the SoG, these attenuation processes are strongly influenced by the Fraser River (Loos and Costa 2010). The largest river on Canada's west coast $\left(3660 \mathrm{~m}^{3} \cdot \mathrm{s}^{-1}\right.$ ) (Water Office 2017), the Fraser discharges particles and organic matter into the central SoG in a highly turbid surface plume, particularly during its May/June freshet (Milliman 1980; Kostaschuk et al. 1995; Luternauer et al. 1998; 
Barrie and Currie 2000; Stecko and Bendell-Young 2000). However, a thin, turbid layer persists at the surface of the SoG throughout the year (Johannessen et al. 2005). The Fraser plume, especially in the spring and summer, also presents well-defined inherent optical properties (IOP) with high scattering and absorption as a result of high concentrations of inorganic particulates and dissolved organic matter. The concentrations of suspended particles and chromophoric dissolved organic matter (CDOM) are inversely correlated with salinity, generally decreasing away from the river toward the western and northern parts of the SoG. Chlorophyll $a$ (chl $a$ ) concentration is patchy, and its spatial distribution varies, but its absorption is more dominant in the northern waters (Loos and Costa 2010).

To date, little research has addressed the underwater visible light field or how light is attenuated within the euphotic zone of the waters of the SoG. Here we describe the underwater light environment of the SoG in spring and summer, when the biogeochemistry is the most dynamic. The underwater light environment is described based on its apparent optical properties (AOP), specifically, reflectance, attenuation coefficients of downwelling scalar irradiance, and the average cosine of downwelling irradiance, a measure of the diffusivity of light. We combine field and laboratory data with a radiative transfer model to define how the underwater light field varies spatially and with depth during spring and summer conditions. These data are unique for this region, and are relevant for defining light availability for primary production and the heat budget in the ocean. For instance, the Regional Ocean Modeling System parameterization of the downwelling flux of photosynthetically available radiation (PAR, $400-700 \mathrm{~nm}$ ) is based on the vertical attenuation of downwelling light, which is defined according to the Jerlov water classification (Mobley et al. 2015).

\section{Materials and methods}

\section{Study area}

The SoG exhibits estuarine circulation characterized by lower salinity seaward surface flow driven by the discharge of the Fraser and other rivers, and a deep return flow of more saline and nutrient-rich waters from the Pacific Ocean into the Strait (Li et al. 2000). Vigorous tidal mixing occurs in Haro Strait and Boundary Pass (Fig. 1), where deeper waters from the Pacific Ocean are mixed with surface waters (Masson and Cummins 2004). The waters of the SoG within the euphotic zone are influenced by the discharge of the Fraser River to different degrees depending on the season, surface currents, and tides. Thus, the salinity structure in the SoG creates the stratification that is always present in these waters (Tully and Dodimead 1957; Waldichuk 1957).

High concentrations of suspended particles and dissolved organic matter in the surface layer are generally observed, particularly in the Fraser River plume (Pharo and Barnes 1976; Kostaschuk and Luternauer 1989; Kostaschuk et al. 1993; Luternauer et al. 1998; Kostaschuk 2002). Primary productivity is high $\left(\sim 280 \mathrm{gC} \cdot \mathrm{m}^{-2} \cdot \mathrm{year}^{-1}\right)$ and mainly limited by light, as for most of the year nutrients are supplied in excess by inflow of upwelled water from the Pacific Ocean (Thomas and Grill 1977; Stockner et al. 1979; Harrison et al. 1983, 1994; St. John and Pond 1992; Yin et al. 1995, 1997; Mackas and Harrison 1997; Yin and Harrison 2000).

In the SoG, during the spring and summer, waters with the highest attenuation (e.g., beam attenuation coefficient of blue light at $411 \mathrm{~nm}, c_{t^{\prime}}(z, 411) \approx 8.0 \mathrm{~m}^{-1}$ ) and lowest ratio of absorption to scattering $\left(a_{t^{\prime}}(z, 411) / b_{p^{\prime}}(z, 411) \approx 0.4\right)$ are mostly related to the Fraser River plume, due to the high particle concentrations. The Fraser River plume water was defined as optical water mass 1 (OM1) by Loos and Costa (2010). Northern Strait surface waters and waters below the optical attenuation cline, $\mathrm{OM} 2$, are defined as transitional optical waters, and are characterized by lower attenuation 


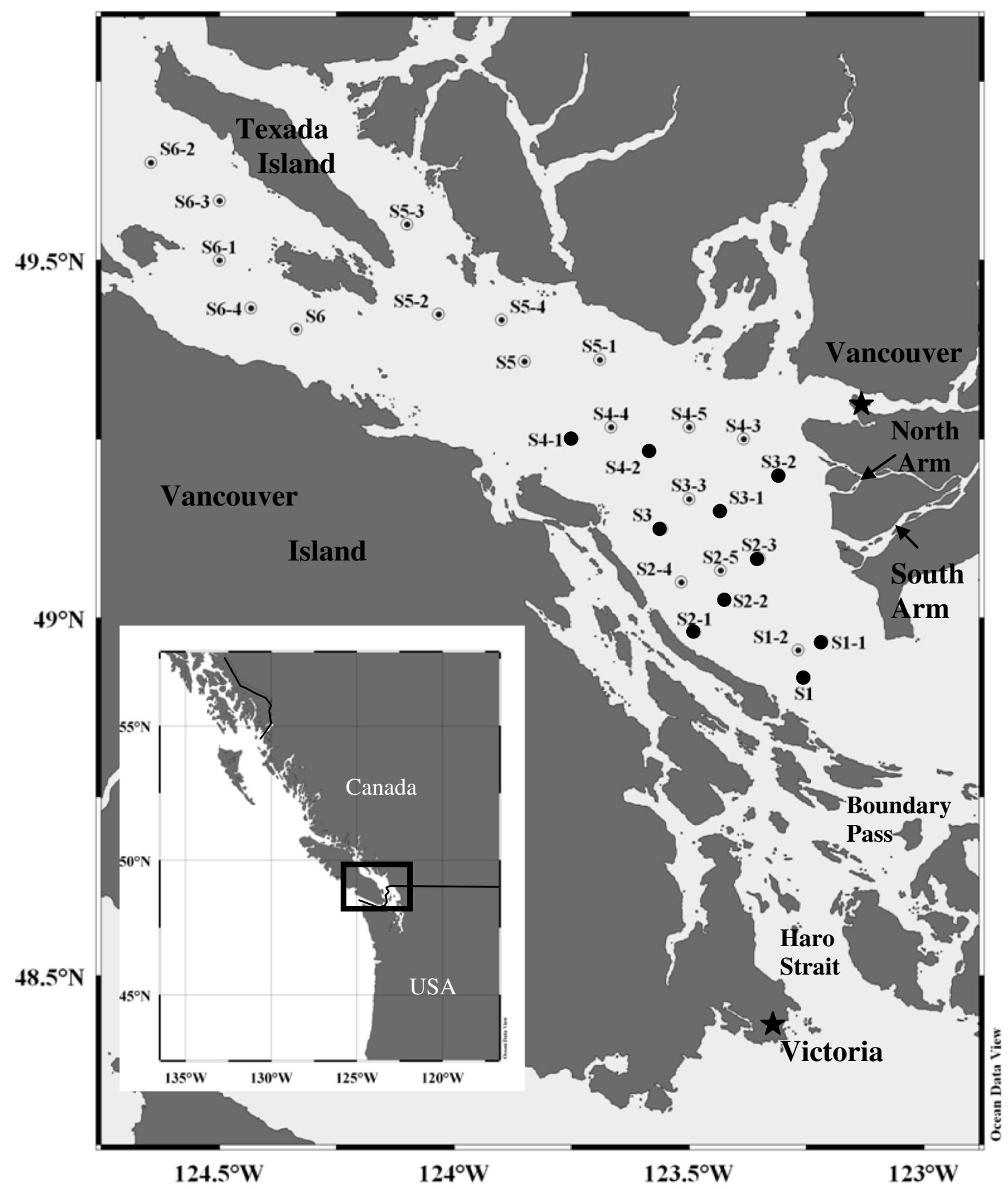

Fig. 1. Study area and sampling stations in the Strait of Georgia, British Columbia, Canada. North and South Arms of the Fraser River are also indicated. April stations are represented as black dots; all stations were sampled in July. 
$\left(c_{t^{\prime}}(z, 411) \approx 1.2 \mathrm{~m}^{-1}\right)$ and higher IOP ratios $\left(a_{t^{\prime}}(z, 411) / b_{p^{\prime}}(0-, 411) \approx 1.0\right)$. Finally, deeper waters $(z \geq 10.0 \mathrm{~m}), \mathrm{OM} 3$, generally exhibited the lowest attenuation $\left(c_{t^{\prime}}(z, 411) \approx 0.5 \mathrm{~m}^{-1}\right)$ and highest absorption to scattering ratios $\left(a_{t^{\prime}}(z, 411) / b_{p^{\prime}}(z, 411) \approx 2.0\right)$, indicating that absorption by CDOM is the dominant process (Loos and Costa 2010).

\section{Data collection}

Optical data (AOP and IOP) and water samples were collected at 11 stations in April 2006 and at 27 stations in July 2006 (Fig. 1), aboard the MSV John Strickland. Stations were chosen to span the optical variability of the waters of the SoG under the influence of the Fraser River, including stations used in previous research (Pawlowicz et al. 2003; Collins 2005; Johannessen et al. 2006). The methods and results for the IOP measurements were described in detail by Loos and Costa (2010) and will not be discussed further in this paper.

Spectral downwelling plane irradiance, $E_{d}(z, \lambda)$, and profiles of spectral upwelling radiance, $L_{u}(z, \lambda)$, were measured with Satlantic Minispec OCR-3000 sensors (400-800 nm; $1 \mathrm{~nm}$ spectral resolution) installed on a free-falling profiler. Above-water spectral downwelling plane irradiance, $E_{s}(0+, \lambda)$, was collected using a Satlantic Minispec OCR-3000 installed at the top of a $6 \mathrm{~m}$ long pole on the upper deck of the MSV Strickland to avoid shadowing. Underwater radiance reflectance, $R_{r}(z, \lambda)$, was computed using irradiance and radiance from the surface to the $1 \%$ penetration depth, $Z_{1 \%}$, as follows (Mobley 1995):

$$
R_{r}(z, \lambda)=\frac{L_{u}(z, \lambda)}{E_{d}(z, \lambda)}\left(\mathrm{sr}^{-1}\right)
$$

The data were processed and binned to $1 \mathrm{~m}$ depth intervals. The reflectance presented in eq. (1) is also known as the "remote sensing ratio" (Mobley 2017) as $L_{u}(z, \lambda)$ and $E_{d}(z, \lambda)$ were measured in the water column (0-) for any depth. This reflectance is different from the commonly used "remote sensing reflectance", which is measured above the water $(0+)$ at the water-air interface and uses water leaving radiance (the total upward radiance minus the surface-reflected sky radiance), $L_{w}(\lambda)$, instead of $L_{u}(z, \lambda)$. The relationship between the two is usually assumed to be: $L_{w}(\lambda) \approx 0.544$ $L_{u}(z, \lambda)$ (Mobley 1999; Doxaran et al. 2004). Our reflectances were collected under water, so there are differences in magnitude between our underwater reflectances and the remote sensing reflectances due to the different refraction indices of the two media (water and air). We were only interested in what was happening within the water column. Assuming $E_{d}$ is the same for both measurements (realistically they will be different simply due to the logistics of acquiring these data in the field), the remote sensing reflectances at the water-air interface $(0+)$ will be lower than our remote sensing ratios. The results we have presented here are primarily for comparison with the underwater reflectances.

The diffuse attenuation coefficient for spectral downwelling plane irradiance, $K_{\mathrm{Ed}}(z, \lambda)$, was calculated as follows (Mobley 1995):

$$
K_{\mathrm{Ed}}(z, \lambda)=-\frac{1}{E_{d}(z, \lambda)} \frac{\mathrm{d} E_{d}(z, \lambda)}{\mathrm{d} z}\left(\mathrm{~m}^{-1}\right)
$$

$Z_{1 \%}$ of PAR was determined from the ratio of in-water spectral downwelling plane irradiance, $E_{d}(z, \mathrm{PAR})$, to above-water downwelling plane irradiance, $E_{s}(0+, \mathrm{PAR}) . Z_{1 \%}$ is approximately equivalent to the depth of the euphotic zone, $Z_{\mathrm{eu}}$ (Kirk 1994; Behrenfeld and Falkowski 1997).

Seabird SBE 37SI conductivity-temperature-depth data were also acquired simultaneously with the optical data and binned to $1 \mathrm{~m}$ depth intervals. 


\section{Modelling}

\section{HydroLight radiative transfer modelling}

Numerical modelling of the optical properties of the waters of the SoG was performed with HydroLight 4.3 (Sequoia Scientific, Inc.) to calculate scalar irradiance, $E_{o}(z, \lambda)$, and the average cosine of downwelling irradiance $(\bar{\mu}(z, \lambda)) . E_{o}(z, \lambda)$ accounts for incoming light over all angles (Mobley 2001), whereas $E_{d}(z, \lambda)$ is limited to light propagating downward and $E_{u}(z, \lambda)$ to light propagating upward only. $E_{o}(z, \lambda)$ better describes the irradiance available for photosynthesis from all directions (Bergmann et al. 2004).

HydroLight carries out radiative transfer calculations through invariant imbedding techniques that require IOP and environmental conditions as inputs (Mobley 1994). The HydroLight model was first validated for the study area using quantities that were measured in the field $\left(E_{d}(z, \lambda), L_{u}(z, \lambda), K_{\mathrm{Ed}}(z, \lambda)\right.$, and $R_{r}(z, \lambda)$; Table 1$)$. The entire set of field data was entered into HydroLight's model ABACBB to solve the radiative transfer equations. The ABACBB model separated the optical constituents into pure water, particulate matter (detritus and phytoplankton), and CDOM. The input dataset consisted of measured optical properties $\left(c_{t^{\prime}}(z, \lambda), a_{t^{\prime}}(z, \lambda), a_{c^{\prime}}(z, \lambda)\right)$, reported by Loos and Costa (2010) (spectral range 400-700 nm), as well as pure water absorption values (Pope and Fry 1997), chl $a$ concentration (from HPLC measurements (Loos and Costa 2010)), wind speed (collected with the vessel's anemometer), cloud cover (assessed visually), air pressure (collected with the vessel's onboard hygrometer), measured above-water spectral downwelling plane irradiance, $E_{d}(0+, \lambda)$, and date and time of field sampling. To ensure that the HydroLight output would closely match possible in situ conditions, it was necessary to input backscattering ratios, $b_{b^{\prime}}(z, \lambda) / b_{t^{\prime}}(z, \lambda)$. However, as $b_{b^{\prime}}(z, \lambda)$ had not been measured in situ, those ratios were chosen from the HydroLight library and input as Fournier-Forand (FF) scattering phase functions (Bergmann et al. 2004). FF values were optimized for each station (values ranging from 0.004 to 0.028 ) by examining the closure between in situ and modelled $R_{r}(z, \lambda)$. All simulations were performed from the surface to $Z_{1 \%}$. Modelled $E_{d}(z, \lambda), L_{u}(z, \lambda), K_{\mathrm{Ed}}(z, \lambda)$, and $R_{r}(z, \lambda)$ were then compared with in situ measured data to assess the performance of the simulation by analyzing the coefficient of determination, $r^{2}$, and the slope of the line of best fit (Table 1 ).

\section{Results and discussion}

\section{Hydrographic data and water optical constituents}

The average discharge of the Fraser River was $2578 \mathrm{~m}^{3} \cdot \mathrm{s}^{-1}$ in April 2006, and $3933 \mathrm{~m}^{3} \cdot \mathrm{s}^{-1}$ in July (high but not peak discharge, bracketing the May-June freshet). The surface water of the SoG was

Table 1. Relationships between measured and modelled variables ( $r^{2}$ and slope of the line of best fit).

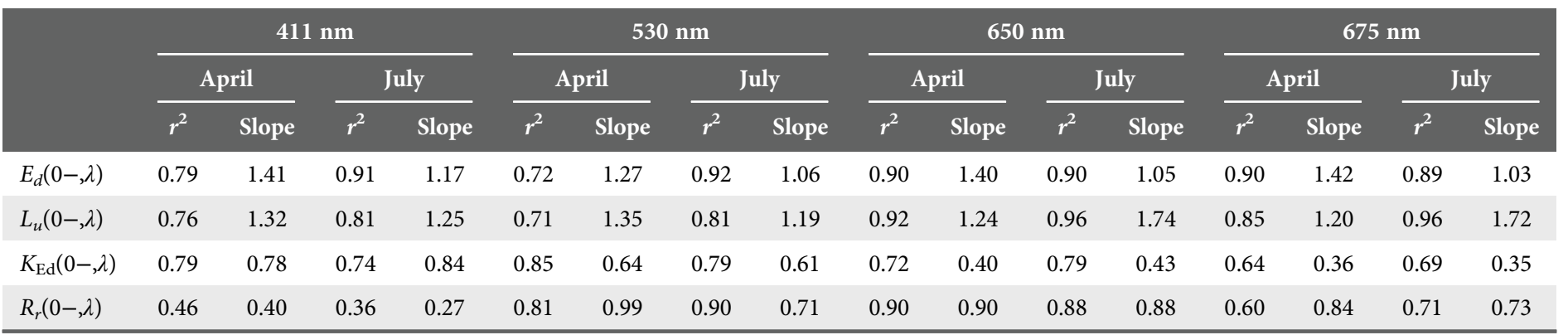

Note: $E_{d}(z, \lambda)$, spectral downwelling plane irradiance; $L_{u}(z, \lambda)$, spectral upwelling radiance; $K_{\mathrm{Ed}}(z, \lambda)$ downwelling irradiance attenuation coefficient; $R_{r}(z, \lambda)$, underwater radiance reflectance; $0-$, in the water. 
stratified in both April and July, with a well-defined halocline and thermocline, both of which were strongest near the Fraser River and weakened westward and away from the plume. The hydrographic and biogeophysical properties of the OMs were previously defined by Loos and Costa (2010).

\section{Optical dynamics}

The in situ and modelled optical data allowed for a description of the light climate in the SoG waters in spring and summer. Generally, the quality and quantity of the in-water light field differed depending on how light was attenuated as a result of different optical constituents.

The reflectance spectra varied in magnitude and shape among OMs and at different times of the year. However, there was a clear transition from waters dominated by the Fraser plume (OM1), through a mixture of plume and Strait waters (OM2), into northern and deeper waters (OM3) (Fig. 2).

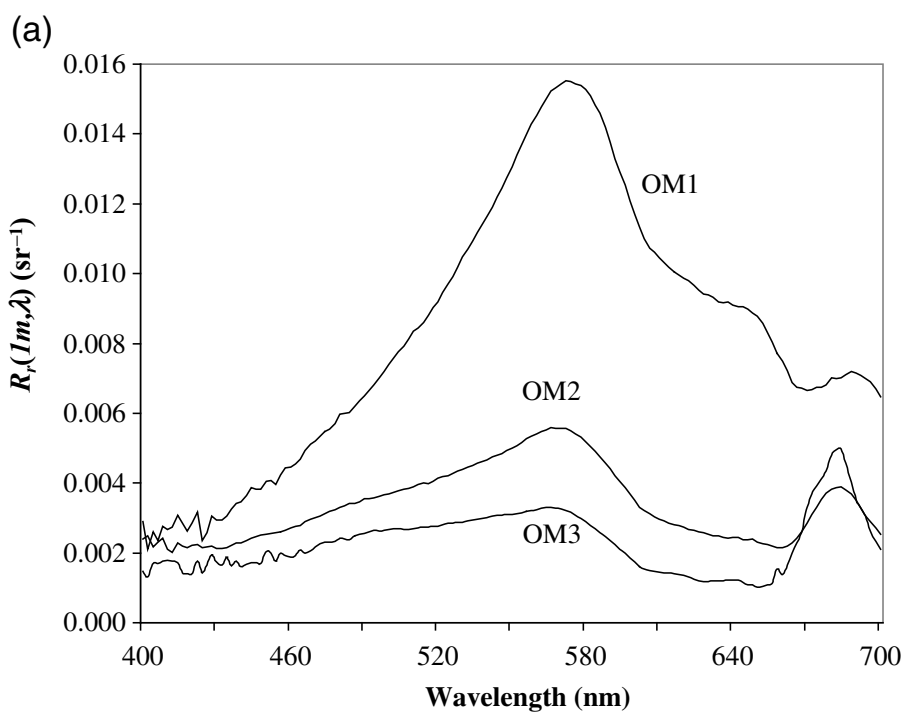

(b)

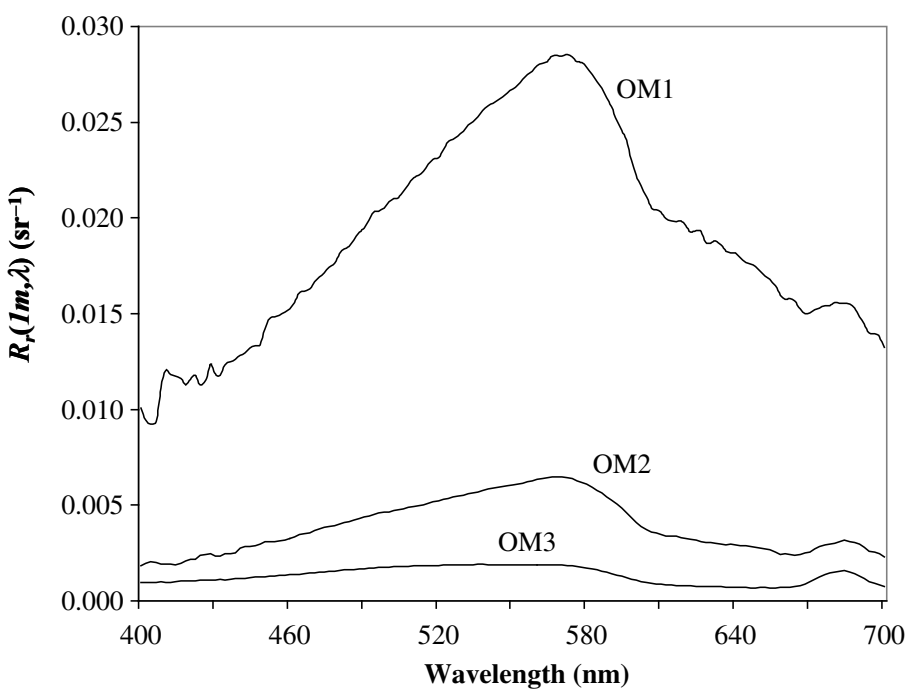

Fig. 2. Means of radiance reflectance, $R_{r}(z, \lambda)$, for the first metre of each optical water mass (OM) in (a) spring and (b) summer 2006. Note the different $y$-axis scales in plots (a) and (b). 
$R_{r}(z, \lambda)$ was highest in OM1 $\left(0.021 \mathrm{sr}^{-1}\right.$ in April and $0.040 \mathrm{sr}^{-1}$ in July), and lowest in OM3 (deeper water) (Fig. 2). The strong reflectance in OM1 is a consequence of the high scattering caused by suspended particles and the low absorption-to-scattering ratio for these waters that was observed by Loos and Costa (2010).

The shape of the reflectance spectra varied among water masses and between the spring and summer conditions. There was a clear transition from waters dominated by the Fraser plume (OM1), through a mixture of plume and Strait waters (OM2), into northern and deeper waters (OM3) (Fig. 2). Generally, the reflectance was lowest at $400-450 \mathrm{~nm}$ (purple-blue), and peaked at 520-640 nm (yellow-green). The yellow-green peak was less pronounced in OM2 and OM3 than in OM1, consistent with the observation that in OM2 and OM3 absorption by CDOM contributed more to the total attenuation of blue light than did absorption and scattering by suspended particles (Loos and Costa 2010).

The reflectance minimum at $675 \mathrm{~nm}$ and small peak at $685 \mathrm{~nm}$ (due to absorption and fluorescence of chl $a$, respectively) were less pronounced in OM1 (Fig. 2). This was a consequence of the absorption by $\operatorname{CDOM}\left(1.0 \mathrm{~m}^{-1}\right.$ in April and $0.53 \mathrm{~m}^{-1}$ in July) and increased scattering due to high concentrations of suspended particles (6.9 mg. $\mathrm{L}^{-1}$ in April, $9.9 \mathrm{mg} \cdot \mathrm{L}^{-1}$ in July) in these waters (Loos and Costa 2010), which overwhelmed the effects of chlorophyll.

The high turbidity of the OM1 waters played a strong role in the attenuation coefficient of downwelling irradiance, $K_{\mathrm{Ed}}(z, \lambda)$, and follows Jerlov's classification of waters with the highest turbidity. Jerlov's water body classification scheme is based on the vertical attenuation of downwelling irradiance. In all, there are five typical open ocean spectra (I, IA, IB, II, and III) and nine typical coastal spectra (1-9), with turbidity increasing with class number (Jerlov 1976). In April, in situ $K_{\mathrm{Ed}}(z, \lambda)$ in OM1 was slightly higher than Jerlov's most turbid classification for coastal waters (Fig. 3). In July, $K_{\mathrm{Ed}}(z, \lambda)$ in OM1 was similar to that of Jerlov's Type 9 in the short wavelengths but exceeded Type 9 above $500 \mathrm{~nm}$. Vertical profiles of $E_{d}(z, \mathrm{PAR}) / E_{s}(0+, \mathrm{PAR})$ further corroborate the fact that light was attenuated with depth most rapidly in the turbid waters of the Fraser River plume (Fig. 4). The magnitude of $K_{\mathrm{Ed}}(z, \lambda)$ decreased with distance from the Fraser River; OM3 waters were the clearest of all three OMs, particularly in July, when $K_{\mathrm{Ed}}(z, \lambda)$ in OM3 was similar to Jerlov Type 1. In April, OM3 waters were somewhere between Jerlov types 3 and 5 (Fig. 3).

\section{Scalar irradiance and the average cosine}

For brevity, optical results will be discussed for four key wavelengths in the blue (411 nm), green $(530 \mathrm{~nm})$, and red $(650$ and $675 \mathrm{~nm})$ parts of the electromagnetic spectrum to show the dynamics of light. HydroLight output predicted all the measured variables with $p<0.05$. The $p$-value was used here simply to demonstrate the significance of the calculated values. In our case, we assumed that $p<0.05$ indicated that the modelled results were significant and can be trusted. The relationships were stronger for $E_{d}(z, \lambda), L_{u}(z, \lambda)$, and $K_{\mathrm{Ed}}(z, \lambda)$, which are less sensitive to the geometry of the incoming light (Bukata et al. 1995) than for $R_{r}(z, \lambda)$ (Table 1).

HydroLight output resulted in low values of $\bar{\mu}(z, \lambda)(\sim 0.7$ at $411 \mathrm{~nm})$ for OM1 waters, indicating a very diffuse light field (Fig. 5), whereas $\bar{\mu}(z, \lambda)$ was higher in OM2 and OM3 waters. Light was less diffuse away from the plume and in deep water, as indicated by the increase in $\bar{\mu}(z, \lambda)$ to a maximum of 0.9 at $411 \mathrm{~nm}$ in OM3. The high light diffusivity of OM1 is associated with high scattering caused by inorganic suspended particles. The association of in-water light diffusivity with inorganic or organic dominant matter was further explained based on data from Loos and Costa (2010) and according to the ratio of backscattering to particulate scattering, $b_{b^{\prime}}(z, \lambda) / b_{p^{\prime}}(z, \lambda)$, and parameter $B$ of McKee and Cunningham (2005), which considers the modelled backscattering coefficients and in situ particulate scattering coefficients (eq. (3)). 
(a)

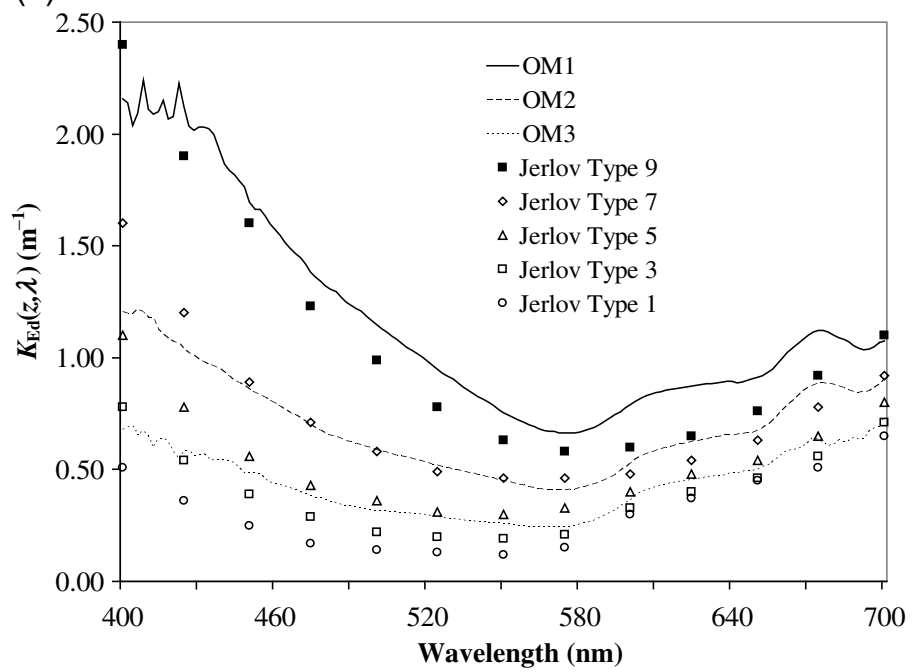

(b)

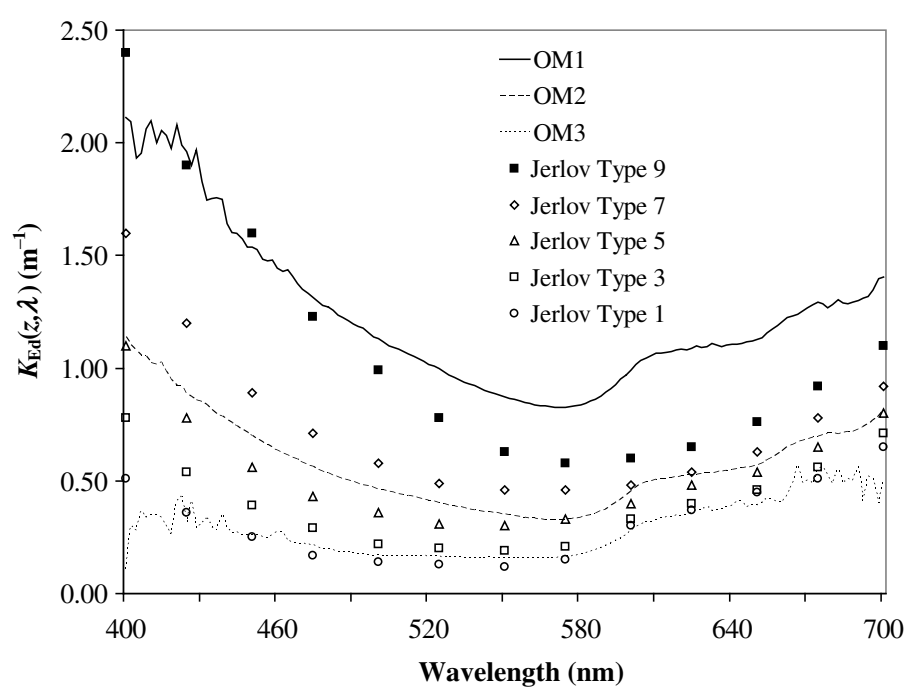

Fig. 3. Downwelling irradiance attenuation coefficient $K_{\mathrm{Ed}}(z, \lambda)$ for (a) spring and (b) summer optical water masses (OMs; lines) and Jerlov coastal water types (symbols).

$$
B_{\mathrm{wd}}=\left[b_{b^{\prime}}(z, 411) / b_{p^{\prime}}(z, 411)\right] /\left[b_{b^{\prime}}(z, 675) / b_{p^{\prime}}(z, 675)\right]
$$

This was demonstrated based on HydroLight-derived backscattering and backscattering ratio (Loos and Costa 2010).

For OM1 waters, $b_{b^{\prime}}(z, \lambda) / b_{p^{\prime}}(z, \lambda)$ values were the highest, decreasing away from the plume and with depth. A high OM1 $b_{b^{\prime}} / b_{p^{\prime}}$ ratio (e.g., 0.012 at $530 \mathrm{~nm}$ ) indicates a high proportion of inorganic particles in the suspended load, because of the high index of refraction of such particles (Twardowski et al. 2001; Boss et al. 2004) and is consistent with the high proportion of inorganic particles in river plume waters (Johannessen et al. 2003). OM2 and OM3 waters had low $b_{b^{\prime}} / b_{p^{\prime}}$ indicating a higher proportion of organic particles in these waters (Table 2). 


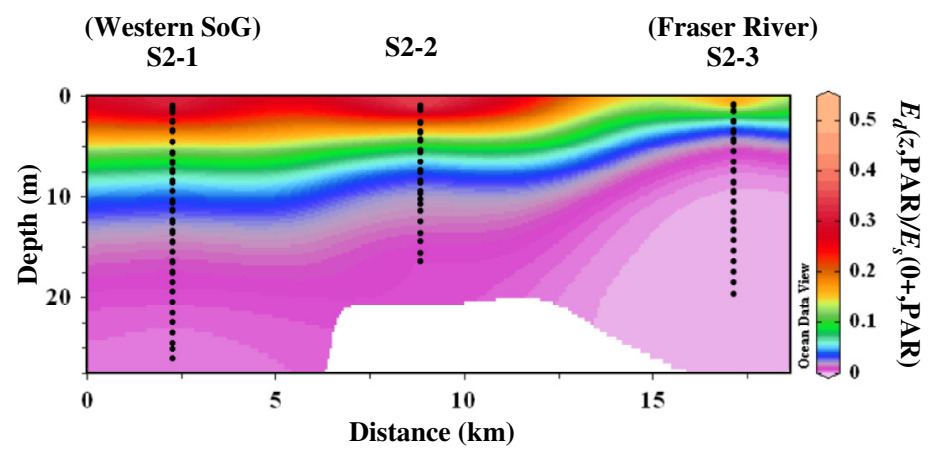

Fig. 4. Vertical profile of the ratio of the in-water spectral downwelling plane irradiance to the above-water downwelling plane irradiance, $E_{d}(z, \mathrm{PAR}) / E_{s}(0+, \mathrm{PAR})$, showing the attenuation of $E_{d}(z, \mathrm{PAR})$ closer to the Fraser River (station S2-3). Less than $10 \%$ of $E_{d}(z, \mathrm{PAR})$ was found below $3 \mathrm{~m}$ at S2-3 in April and July. Interpolation between stations included data from neighbouring stations not depicted in the figure. SoG, Strait of Georgia; PAR, photosynthetically available radiation.

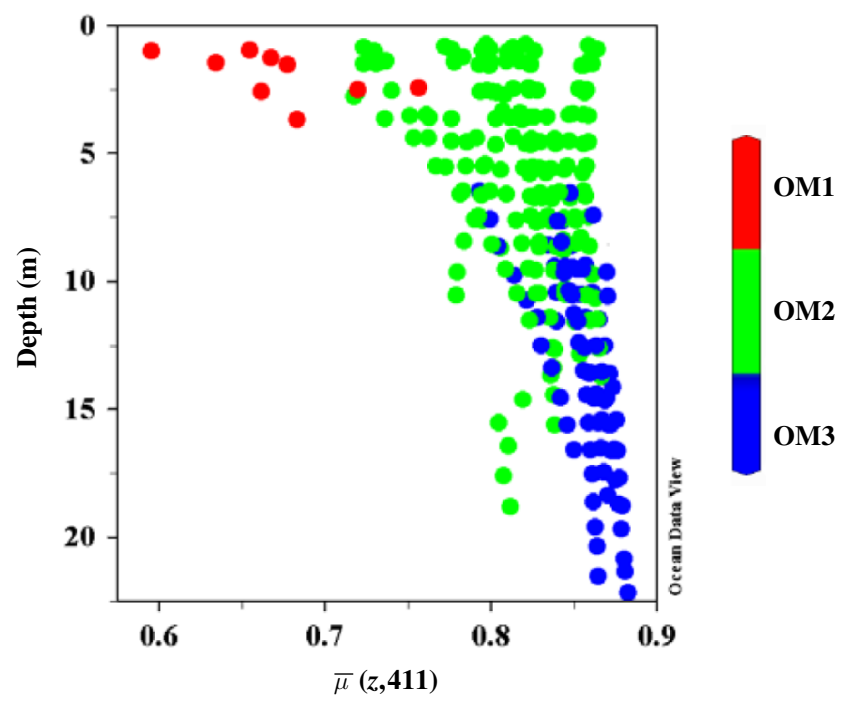

Fig. 5. Average cosine at $411 \mathrm{~nm}$ for all three optical water masses (OMs) in July. Diffusivity increases with decreasing average cosines. OM1 had the lowest average cosines because of their high attenuation due to inorganic particulate scattering.

The relationship between $B_{\mathrm{wd}}$ and $b_{p^{\prime}}(z, 675) / a_{t^{\prime}}(z, 675)$ indicated that scattering in OM1 was less variable and had lower wavelength dependence $\left(B_{\mathrm{wd}} \approx 1.0\right.$ in April and July) than that in OM2 and OM3 waters due to the higher concentration of suspended particles in OM1. The greater wavelength dependence of the scattering coefficient in OM2 is attributed to the organic nature of the particulate, namely phytoplankton.

Modelled normalized scalar irradiance, $n E_{o}(z, \lambda)$, obtained from the ratio $E_{o}(z, \lambda) / E_{o}(0+, \lambda)$, was the lowest in OM1 and indicated that blue and red wavelengths were quickly attenuated within the first $5 \mathrm{~m}$ to below $5 \%$ of the surface intensity (Figs. 6a, 6c). Below this depth, available light was predominantly in the green wavelengths (Fig. 6b). This is also supported by the low $K_{\mathrm{Ed}}(z, 500-600 \mathrm{~nm})$ in the green spectrum (Fig. 4). The modelled attenuation coefficient of scalar 


\begin{tabular}{|c|c|c|c|c|c|c|c|c|c|}
\hline & \multirow{2}{*}{$\begin{array}{l}\text { Optical } \\
\text { water } \\
\text { mass }\end{array}$} & \multicolumn{2}{|c|}{$411 \mathrm{~nm}$} & \multicolumn{2}{|c|}{$530 \mathrm{~nm}$} & \multicolumn{2}{|c|}{$650 \mathrm{~nm}$} & \multicolumn{2}{|c|}{$675 \mathrm{~nm}$} \\
\hline & & April & July & April & July & April & July & April & July \\
\hline \multirow[t]{3}{*}{$\bar{\mu}(z, \lambda)$} & OM1 & $0.77 \pm 0.03$ & $0.67 \pm 0.05$ & $0.61 \pm 0.03$ & $0.52 \pm 0.06$ & $0.62 \pm 0.05$ & $0.55 \pm 0.09$ & $0.66 \pm 0.05$ & $0.57 \pm 0.10$ \\
\hline & OM2 & $0.81 \pm 0.04$ & $0.82 \pm 0.03$ & $0.71 \pm 0.06$ & $0.74 \pm 0.05$ & $0.78 \pm 0.05$ & $0.80 \pm 0.05$ & $0.73 \pm 0.07$ & $0.75 \pm 0.07$ \\
\hline & OM3 & $0.85 \pm 0.02$ & $0.90 \pm 0.02$ & $0.76 \pm 0.04$ & $0.78 \pm 0.04$ & $0.84 \pm 0.03$ & $0.85 \pm 0.03$ & $0.64 \pm 0.14$ & $0.63 \pm 0.16$ \\
\hline \multirow{3}{*}{$\begin{array}{l}E_{d}(0-, \lambda)\left(\times 10^{2}\right) \\
\left(\mathrm{W} \cdot \mathrm{m}^{-2} \cdot \mathrm{nm}^{-1}\right)\end{array}$} & OM1 & $0.91 \pm 1.83$ & $2.19 \pm 3.27$ & $8.55 \pm 8.00$ & $14.57 \pm 11.30$ & $7.00 \pm 6.10$ & $10.24 \pm 8.13$ & $5.26 \pm 5.52$ & $8.28 \pm 7.56$ \\
\hline & $\mathrm{OM} 2$ & $1.96 \pm 3.51$ & $3.44 \pm 8.51$ & $17.76 \pm 14.04$ & $19.18 \pm 23.15$ & $6.75 \pm 8.25$ & $8.23 \pm 13.96$ & $3.70 \pm 5.38$ & $5.75 \pm 11.49$ \\
\hline & OM3 & $0.67 \pm 2.16$ & $0.02 \pm 0.04$ & $7.04 \pm 6.30$ & $4.40 \pm 3.82$ & $1.44 \pm 3.04$ & $0.21 \pm 0.32$ & $0.85 \pm 2.45$ & $0.06 \pm 0.10$ \\
\hline \multirow{3}{*}{$\begin{array}{l}L_{u}(0-, \lambda)\left(\times 10^{2}\right) \\
\left(\mathrm{W} \cdot \mathrm{m}^{-2} \cdot \mathrm{sr}^{-1} \cdot \mathrm{nm}^{-1}\right)\end{array}$} & OM1 & $0.002 \pm 0.005$ & $0.015 \pm 0.024$ & $0.078 \pm 0.082$ & $0.25 \pm 0.26$ & $0.058 \pm 0.066$ & $0.17 \pm 0.23$ & $0.037 \pm 0.048$ & $0.13 \pm 0.18$ \\
\hline & OM2 & $0.003 \pm 0.005$ & $0.005 \pm 0.011$ & $0.074 \pm 0.078$ & $0.059 \pm 0.070$ & $0.013 \pm 0.0 .22$ & $0.013 \pm 0.025$ & $0.016 \pm 0.020$ & $0.015 \pm 0.024$ \\
\hline & OM3 & $0.001 \pm 0.002$ & $\begin{array}{c}3.53 \times 10^{-5} \pm \\
5.99 \times 10^{-5}\end{array}$ & $0.023 \pm 0.026$ & $0.010 \pm 0.007$ & $0.001 \pm 0.003$ & $\begin{array}{c}2.19 \times 10^{-4} \pm \\
2.49 \times 10^{-4}\end{array}$ & $0.003 \pm 0.005$ & $\begin{array}{c}6.54 \times 10^{-4} \pm \\
6.26 \times 10^{-4}\end{array}$ \\
\hline \multirow[t]{3}{*}{$K_{\mathrm{Ed}}(0-, \lambda)\left(\mathrm{m}^{-1}\right)$} & OM1 & $2.28 \pm 0.52$ & $2.01 \pm 0.67$ & $0.69 \pm 0.14$ & $0.84 \pm 0.35$ & $0.68 \pm 0.06$ & $0.87 \pm 0.22$ & $0.87 \pm 0.06$ & $1.01 \pm 0.19$ \\
\hline & OM2 & $0.75 \pm 0.22$ & $0.73 \pm 0.27$ & $0.26 \pm 0.08$ & $0.26 \pm 0.10$ & $0.52 \pm 0.07$ & $0.49 \pm 0.06$ & $0.69 \pm 0.13$ & $0.61 \pm 0.09$ \\
\hline & OM3 & $0.48 \pm 0.09$ & $0.43 \pm 0.10$ & $0.15 \pm 0.03$ & $0.15 \pm 0.03$ & $0.42 \pm 0.02$ & $0.42 \pm 0.02$ & $0.48 \pm 0.11$ & $0.45 \pm 0.10$ \\
\hline \multirow[t]{3}{*}{$R_{r}(0-, \lambda)\left(\times 10^{3}\right)\left(\mathrm{sr}^{-1}\right)$} & OM1 & $2.00 \pm 0.51$ & $6.00 \pm 2.00$ & $8.00 \pm 2.00$ & $17.00 \pm 7.00$ & $7.00 \pm 3.00$ & $15.00 \pm 10.00$ & $6.00 \pm 2.00$ & $13.00 \pm 8.00$ \\
\hline & OM2 & $1.58 \pm 0.58$ & $1.70 \pm 0.60$ & $4.00 \pm 1.95$ & $4.00 \pm 3.00$ & $1.53 \pm 0.83$ & $1.78 \pm 1.78$ & $9.00 \pm 10.00$ & $8.00 \pm 9.00$ \\
\hline & OM3 & $1.40 \pm 0.29$ & $1.45 \pm 0.42$ & $3.00 \pm 1.00$ & $2.00 \pm 1.44$ & $1.60 \pm 1.15$ & $1.83 \pm 1.66$ & $28.00 \pm 27.00$ & $29.00 \pm 28.00$ \\
\hline \multirow[t]{3}{*}{$b_{b^{\prime}}(z, \lambda)\left(\mathrm{m}^{-1}\right)$} & OM1 & $0.041 \pm 0.015$ & $0.091 \pm 0.050$ & $0.038 \pm 0.015$ & $0.088 \pm 0.052$ & $0.036 \pm 0.014$ & $0.083 \pm 0.052$ & $0.035 \pm 0.015$ & $0.082 \pm 0.053$ \\
\hline & OM2 & $0.007 \pm 0.005$ & $0.008 \pm 0.006$ & $0.008 \pm 0.005$ & $0.007 \pm 0.006$ & $0.007 \pm 0.005$ & $0.007 \pm 0.006$ & $0.006 \pm 0.005$ & $0.006 \pm 0.005$ \\
\hline & OM3 & $0.002 \pm 0.001$ & $0.002 \pm 0.002$ & $0.003 \pm 0.002$ & $0.002 \pm 0.001$ & $0.002 \pm 0.002$ & $0.002 \pm 0.001$ & $0.002 \pm 0.001$ & $0.002 \pm 0.001$ \\
\hline \multirow[t]{3}{*}{$b_{b^{\prime}}(z, \lambda) / b_{p^{\prime}}(z, \lambda)$} & OM1 & $0.010 \pm 0.003$ & $0.014 \pm 0.006$ & $0.010 \pm 0.003$ & $0.014 \pm 0.007$ & $0.010 \pm 0.003$ & $0.014 \pm 0.007$ & $0.010 \pm 0.003$ & $0.014 \pm 0.007$ \\
\hline & OM2 & $0.009 \pm 0.005$ & $0.012 \pm 0.006$ & $0.009 \pm 0.005$ & $0.012 \pm 0.007$ & $0.009 \pm 0.005$ & $0.012 \pm 0.007$ & $0.009 \pm 0.005$ & $0.012 \pm 0.007$ \\
\hline & OM3 & $0.008 \pm 0.004$ & $0.011 \pm 0.007$ & $0.008 \pm 0.004$ & $0.011 \pm 0.007$ & $0.008 \pm 0.004$ & $0.011 \pm 0.007$ & $0.008 \pm 0.004$ & $0.011 \pm 0.007$ \\
\hline \multirow[t]{3}{*}{$n E_{o}(0-, \lambda)$} & OM1 & $0.016 \pm 0.031$ & $0.029 \pm 0.047$ & $0.154 \pm 0.141$ & $0.216 \pm 0.180$ & $0.159 \pm 0.141$ & $0.152 \pm 0.130$ & $0.113 \pm 0.121$ & $0.117 \pm 0.114$ \\
\hline & OM2 & $0.021 \pm 0.036$ & $0.031 \pm 0.064$ & $0.172 \pm 0.111$ & $0.152 \pm 0.137$ & $0.071 \pm 0.076$ & $0.079 \pm 0.110$ & $0.039 \pm 0.051$ & $0.055 \pm 0.091$ \\
\hline & OM3 & $0.014 \pm 0.042$ & $0.000 \pm 0.001$ & $0.120 \pm 0.106$ & $0.036 \pm 0.022$ & $0.029 \pm 0.062$ & $0.002 \pm 0.003$ & $0.018 \pm 0.049$ & $0.001 \pm 0.001$ \\
\hline
\end{tabular}

Note: $\bar{\mu}(z, \lambda)$, average cosine of downwelling irradiance; $E_{d}(z, \lambda)$, spectral downwelling plane irradiance; $L_{u}(z, \lambda)$, spectral upwelling radiance; $K_{\mathrm{Ed}}(z, \lambda)$ downwelling irradiance attenuation coefficient; $R_{r}(z, \lambda)$, underwater radiance reflectance; $b_{b^{\prime}}(z, \lambda)$, particulate backscattering; $b_{p^{\prime}}(z, \lambda)$ particulate scattering; $n E_{o}(z, \lambda)$, normalized scalar irradiance; $0-$, in the water. 

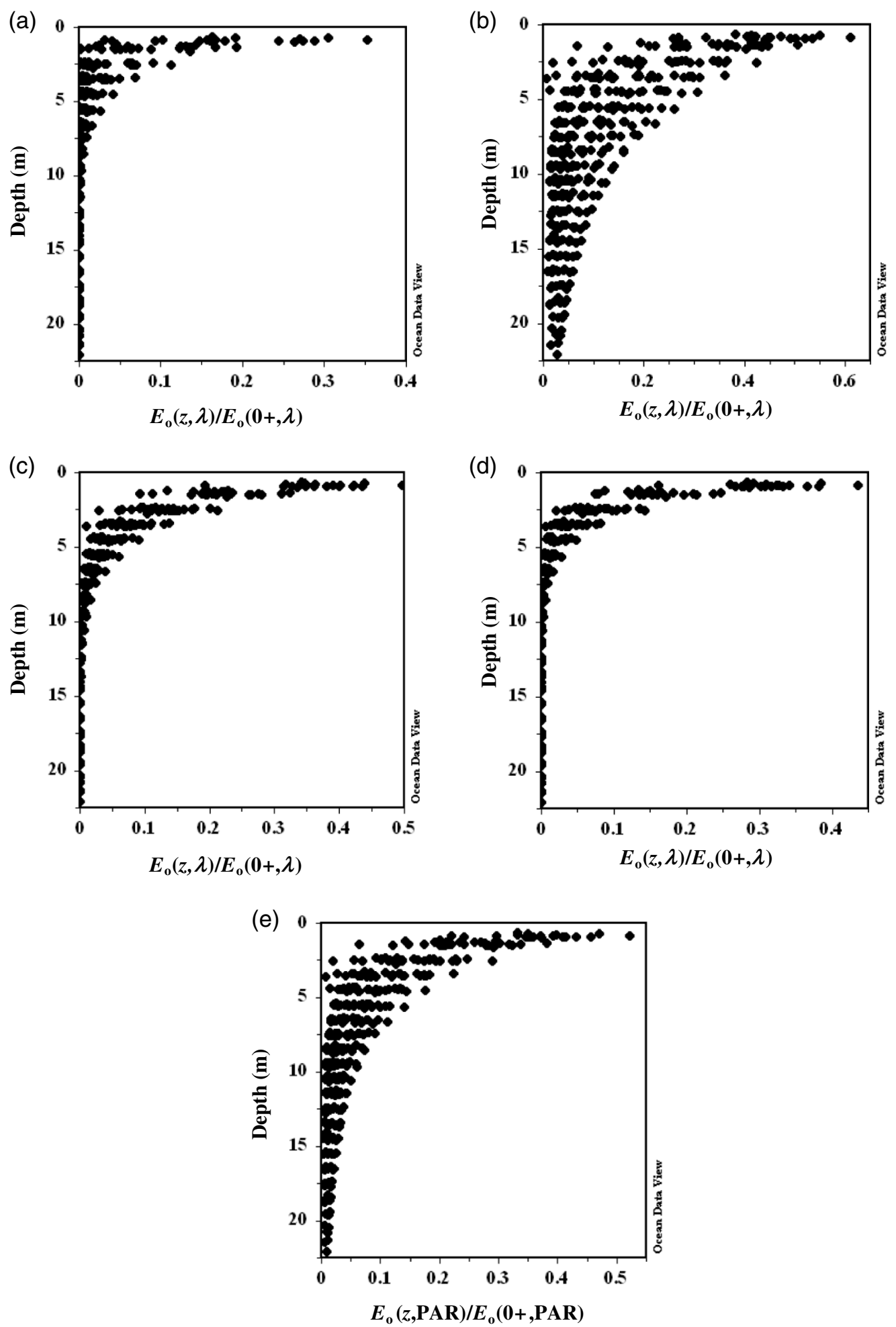

Fig. 6. Ratio between in-water downwelling scalar irradiance and above-water downwelling scalar irradiance in spring and summer at (a) $411 \mathrm{~nm}$, (b) $530 \mathrm{~nm}$, (c) $650 \mathrm{~nm}$, and (d) $675 \mathrm{~nm}$ for all stations; (e) ratio between photosynthetically available radiation (PAR) in-water downwelling scalar irradiance and abovewater downwelling scalar irradiance in April and July for all stations. 
irradiance, $K_{\mathrm{Eo}}(z, \mathrm{PAR})\left(0.11-2.90 \mathrm{~m}^{-1}\right.$; Table 3$)$ in spring and summer was similar to values reported by Stockner et al. (1979) and Harrison et al. (1991) in the waters of the SoG during winter and spring.

Table 3. Modelled and in situ radiometric quantities and apparent optical properties.

\begin{tabular}{|c|c|c|c|}
\hline Month & Station & $\begin{array}{c}\text { Modelled } K_{\mathrm{Eo}}(z, \mathrm{PAR}) \\
(\text { mean })\left(\mathrm{m}^{-1}\right)\end{array}$ & $\begin{array}{c}\text { Modelled } K_{\mathrm{Ed}}\left(0_{-}, \mathrm{PAR}\right) \\
(\text { mean })\left(\mathrm{m}^{-1}\right)\end{array}$ \\
\hline \multirow[t]{11}{*}{ April } & S1-1 & 0.361 & 0.356 \\
\hline & S1 & 0.288 & 0.288 \\
\hline & S2-1 & 0.169 & 0.169 \\
\hline & S2-2 & 0.240 & 0.245 \\
\hline & S2-3 & 0.998 & 0.963 \\
\hline & S3 & 0.181 & 0.182 \\
\hline & S3-1 & 0.260 & 0.256 \\
\hline & S3-2 & 0.658 & 0.653 \\
\hline & S4-1 & 0.221 & 0.220 \\
\hline & S4-2 & 0.337 & 0.338 \\
\hline & S4-3 & 0.478 & 0.491 \\
\hline \multirow[t]{19}{*}{ July } & S1-1 & 0.306 & 0.308 \\
\hline & S1-2 & 0.254 & 0.253 \\
\hline & S1 & 0.232 & 0.232 \\
\hline & S2-1 & 0.286 & 0.291 \\
\hline & S2-2 & 0.400 & 0.400 \\
\hline & S2-3 & 1.957 & 1.900 \\
\hline & S3 & 0.358 & 0.333 \\
\hline & S3-1 & 0.563 & 0.565 \\
\hline & S3-2 & 0.648 & 0.618 \\
\hline & S3-3 & 0.393 & 0.388 \\
\hline & S4-1 & 0.211 & 0.213 \\
\hline & S4-2 & 0.412 & 0.415 \\
\hline & S4-3 & 0.473 & 0.475 \\
\hline & S5 & 0.381 & 0.387 \\
\hline & S5-1 & 0.264 & 0.268 \\
\hline & S5-2 & 0.442 & 0.441 \\
\hline & S6 & 0.255 & 0.257 \\
\hline & S6-1 & 0.237 & 0.237 \\
\hline & S6-2 & 0.283 & 0.279 \\
\hline
\end{tabular}

Note: $K_{\mathrm{Eo}}(z, \mathrm{PAR})$, scalar irradiance attenuation coefficient; $K_{\mathrm{Ed}}(0-, \mathrm{PAR})$, downwelling irradiance attenuation coefficient; PAR, photosynthetically available radiation, $0-$, in the water. 
Virtually none of the light that enters the SoG passes all the way through the surface estuarine outflow layer. The depth of separation between the outflowing and inflowing layers has been modelled at $50 \mathrm{~m}$ (Pawlowicz et al. 2007) and $30 \mathrm{~m}$ (Riche and Pawlowicz 2014), and the depth of the Fraser River plume at $15 \mathrm{~m}$ (Johannessen et al. 2006; Masson 2006). The more highly depth-resolved profiles shown here (Figs. 2, 7) suggest that most of the light field is attenuated by the fresh water contained within the uppermost $7 \mathrm{~m}$ in spring and summer.

By $15 \mathrm{~m}$, only green light remains (Fig. 7), and even then only in areas away from the Fraser River plume (S4, S5, and S6 group of stations in Fig. 1). By $30 \mathrm{~m}$, all of the downwelling irradiance has been

(a)

Irradiance, $E_{d}\left(\mu \mathrm{Wcm}^{-2} \mathrm{~s}^{-1}\right)$

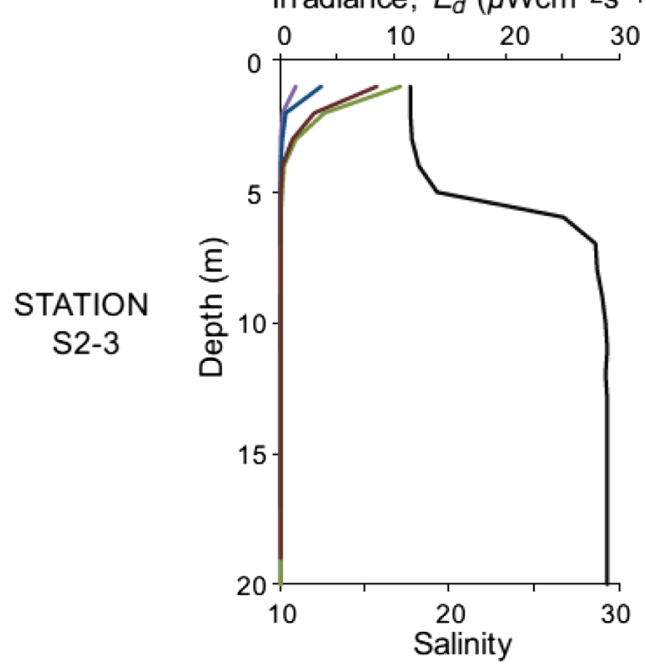

(c)

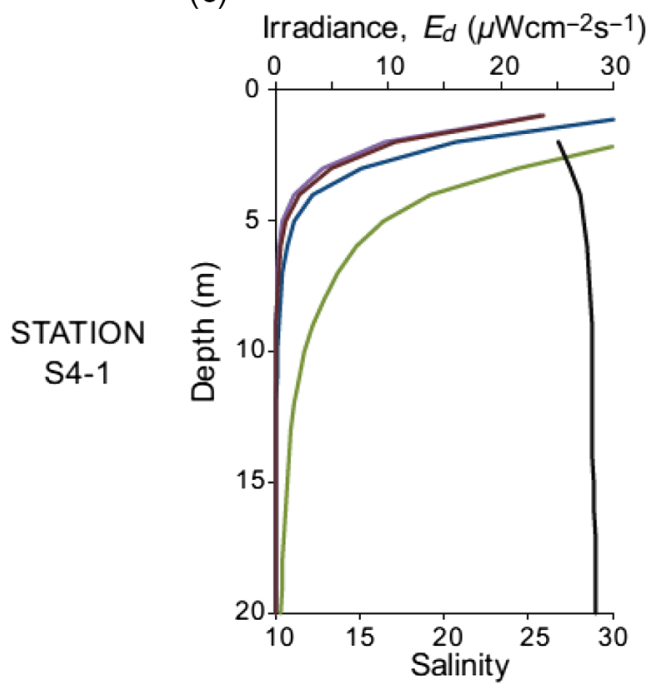

(b)

JULY Irradiance, $E_{d}\left(\mu \mathrm{Wcm}^{-2} \mathrm{~s}^{-1}\right)$

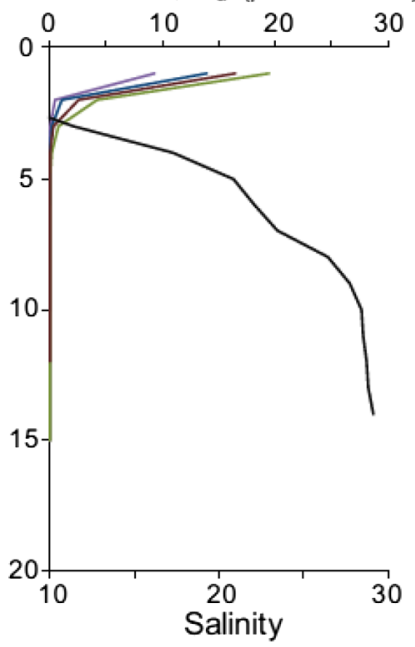

(d)
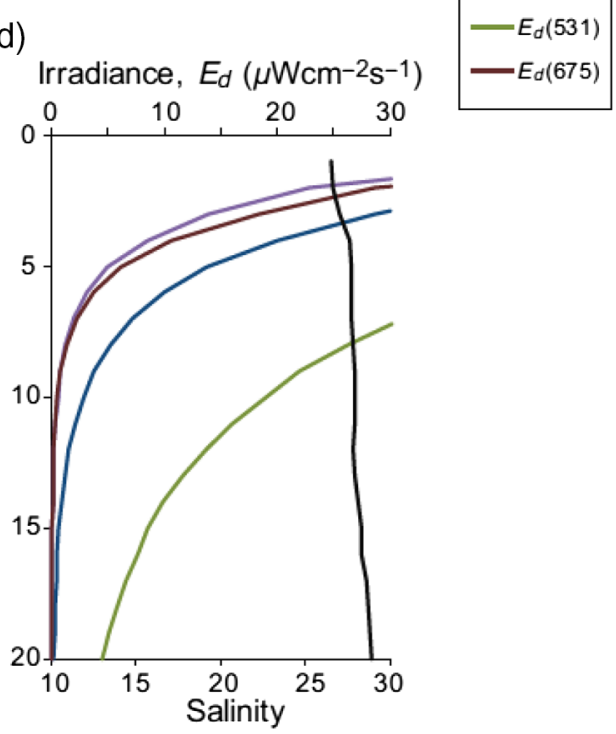

Fig. 7. Depth profiles of salinity and irradiance (at 411, 443, 531, and $675 \mathrm{~nm}$ ) in April and July inside (S2-3) and outside (S4-1) the Fraser River plume. 
absorbed within the water column (Loos and Costa 2010) or reflected back out of it (Figs. 3, 7). Figure 2 shows the high reflectance for the OM1 waters. Consequently, all of the light is attenuated within the outflowing surface layer, which has a residence time of approximately $10 \mathrm{~d}$ in the Strait (Pawlowicz et al. 2007). This is consistent with the observation by Pawlowicz et al. (2007) that the SoG is a small net exporter of heat, based on the absorption of shortwave (UV + visible) radiation.

$Z_{1 \%}$ was $6.0-22.0 \mathrm{~m}$ in spring and $4.0-23.0 \mathrm{~m}$ in the summer. The depth of $1 \%$ penetration of blue radiation at one of the chlorophyll absorbance peaks $(443 \mathrm{~nm}$ ) was always shallower than $9.0 \mathrm{~m}$ and often shallower than $5.0 \mathrm{~m}$. Light at all wavelengths was more rapidly attenuated in the summer than in the spring within the river plume, because of the high scattering by inorganic particles and high absorption by CDOM (Loos and Costa 2010). However, away from the plume, blue wavelengths were more rapidly attenuated in the spring, because of the absorption by phytoplankton (Loos and Costa 2010).

The effects of the attenuation of light can be seen in the depth distribution of phytoplankton, which occurs over the top $30 \mathrm{~m}$ in spring, but only over $12 \mathrm{~m}$ in summer (Peña et al. 2016). Primary productivity is always limited by light in the southern Strait, so productivity is actually higher in that region in the summer, when more light is available, than in the spring (Peña et al. 2016). In the central Strait, which includes waters under the strong influence of the Fraser plume, phytoplankton are thought to be usually limited by light and occasionally by nutrients (Peña et al. 2016); although, it can be difficult to differentiate the effects of stratification (nutrient limitation) from those of turbidity (light limitation), as the two factors co-occur in the plume. In fact, primary production is low in the plume in summer (Peña et al. 2016), because both light (due to high attenuation and therefore lower $E_{d}(z, \lambda)$ ) (Fig. 7) and nutrients are in short supply. In the summer, because of their shallow distribution, some phytoplankton are exported from the Strait (Peña et al. 2016) with the illuminated layer of water and absorbed radiation; although, most suspended particles are retained within the Strait (Johannessen et al. 2003).

\section{Conclusions}

The results presented here described the in-water light environment in the SoG, based on in situ observations and radiative transfer modeling. In the SoG, the euphotic zone is shallow due to high turbidity by particles and high absorption by CDOM. In both spring and summer, light generally penetrates $<15 \mathrm{~m}$ into the water column. The light is nearly all attenuated within the outflowing water. Only a small amount of green light passes through the upper layer into the inflowing layer beneath; this likely limits primary production to the uppermost layer.

The waters under the influence of the turbid Fraser River plume showed the highest variability and the most rapid attenuation of light with depth. The rapid attenuation was mostly due to high backscattering by suspended inorganic particles as well as to absorption by CDOM. Reflectance was also highest in the plume waters. A peak at $685 \mathrm{~nm}$, indicating chlorophyll fluorescence, was visible in most reflectance profiles, except in the summer in turbid waters strongly influenced by the Fraser plume. Furthermore, red and blue light were attenuated to $<1 \%$ of their surface intensity within the uppermost $5 \mathrm{~m}$, whereas green and yellow light persisted to about $20 \mathrm{~m}$. This was the result of the high $K_{\mathrm{Ed}}(z, 400 \sim 520 \mathrm{~nm})$. Therefore, $K_{\mathrm{Ed}}(z, \lambda)$ decreased with depth as the concentrations of the absorbing and scattering constituents decreased, with the lowest values (clearest waters) in deeper waters. The very turbid Fraser plume water was characterized by a very diffuse underwater light field, as indicated by the low average cosine ( $\bar{\mu} \approx 0.7$ at $411 \mathrm{~nm}$ ), which increased with depth and with distance from the Fraser River to a maximum in OM3 $(\bar{\mu} \approx 0.9$ at $411 \mathrm{~nm})$.

The surface waters of the SoG are highly stratified. Although ship-based studies seldom resolve the surface layer at more than 5-10 m vertical resolution, the results presented here demonstrate that 
salinity, temperature, turbidity, and irradiance change rapidly with depth over the top $10 \mathrm{~m}$. The strong stratification has consequences for phytoplankton distribution and the energy budget of the system. More highly depth-resolved measurements are necessary to study these processes accurately in the SoG and in other river-dominated coastal margins.

\section{List of abbreviations}

$\begin{array}{ll}\text { AOP } & \text { apparent optical property } \\ \text { CDOM } & \text { chromophoric dissolved organic matter } \\ \text { chl } a & \text { chlorophyll } a \\ \text { FF } & \text { Fournier-Forand } \\ \text { HPLC } & \text { high-performance liquid chromatography } \\ \text { IOP } & \text { inherent optical property } \\ \text { Minispec OCR } & \text { miniature hyperspectral ocean colour radiometer } \\ \text { MSV } & \text { Marine Science Vessel } \\ \text { OM } & \text { optical water mass } \\ \text { PAR } & \text { photosynthetically available radiation } \\ \text { SoG } & \text { Strait of Georgia } \\ \text { SD } & \text { standard deviation }\end{array}$

\section{List of symbols}

\section{Fundamental quantities and other symbols}

$\begin{array}{ll}\mathbf{0 +} & \text { above water } \\ \mathbf{0}- & \text { in the water column } \\ \boldsymbol{B}_{\mathbf{w d}} & \text { wavelength-dependence of the backscattering coefficient } \\ \boldsymbol{p} & \text { probability value } \\ \boldsymbol{r}^{2} & \text { coefficient of determination } \\ \lambda & \text { wavelength (nm) } \\ \boldsymbol{z} & \text { depth (m) } \\ \boldsymbol{Z}_{\mathbf{1} \%} & \text { depth of } 1 \% \text { irradiance }(\mathrm{m}) \\ \boldsymbol{Z}_{\mathbf{e u}} & \text { depth of the euphotic zone }(\mathrm{m})\end{array}$

\section{Radiometric quantities}

$\begin{array}{ll}\boldsymbol{L}_{\boldsymbol{u}} & \text { upwelling radiance }\left(\mathrm{W} \cdot \mathrm{m}^{-2} \cdot \mathrm{sr}^{-1}\right) \\ \boldsymbol{L}_{\boldsymbol{w}} & \text { water-leaving radiance }\left(\mathrm{W} \cdot \mathrm{m}^{-2} \cdot \mathrm{sr}^{-1}\right) \\ \boldsymbol{E}_{\boldsymbol{d}} & \text { in-water downwelling irradiance }\left(\mathrm{W} \cdot \mathrm{m}^{-2}\right) \\ \boldsymbol{E}_{\boldsymbol{s}} & \text { above-water downwelling irradiance }\left(\mathrm{W} \cdot \mathrm{m}^{-2}\right) \\ \boldsymbol{E}_{\boldsymbol{u}} & \text { above-water downwelling irradiance }\left(\mathrm{W} \cdot \mathrm{m}^{-2}\right) \\ \boldsymbol{E}_{\boldsymbol{o}} & \text { scalar irradiance }\left(\mathrm{W} \cdot \mathrm{m}^{-2}\right) \\ \boldsymbol{n} \boldsymbol{E}_{\boldsymbol{o}} & \text { modelled normalized scalar irradiance }\left(\mathrm{W} \cdot \mathrm{m}^{-2}\right)\end{array}$

\section{Inherent optical properties}
$\boldsymbol{a}_{\boldsymbol{t}^{\prime}} \quad$ scattering-corrected absorption coefficient $\left(\mathrm{m}^{-1}\right)$
$\boldsymbol{a}_{\boldsymbol{c}^{\prime}} \quad$ scattering-corrected CDOM absorption coefficient $\left(\mathrm{m}^{-1}\right)$
$\boldsymbol{b}_{\boldsymbol{t}^{\prime}} \quad$ total scattering coefficient without water scattering coefficient $\left(\mathrm{m}^{-1}\right)$
$\boldsymbol{b}_{\boldsymbol{p}^{\prime}} \quad$ particulate scattering coefficient without water scattering coefficient $\left(\mathrm{m}^{-1}\right)$ 
$\boldsymbol{b}_{\boldsymbol{b}^{\prime}} \quad$ modelled particulate backscattering coefficient $\left(\mathrm{m}^{-1}\right)$

$c_{\boldsymbol{t}^{\prime}} \quad$ measured total beam attenuation coefficient without water beam attenuation coefficient $\left(\mathrm{m}^{-1}\right)$

\section{Apparent optical properties}

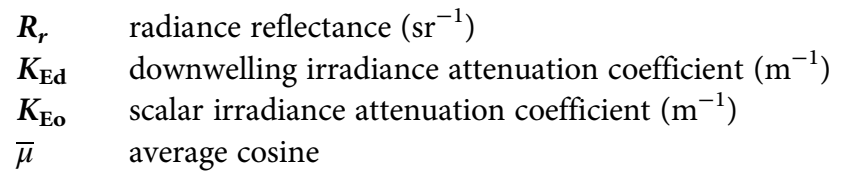

\section{Acknowledgements}

Funding for this research was provided by an NSERC Discovery Grant and an NSERC Ship Time Grant. The authors would like to thank Nicholas Komick (Fisheries and Oceans Canada), Jennifer O'Neill (Artisanal Gold Council), and the crew of the MSV John Strickland, particularly Captain Ken Brown. We appreciate the time and insight of the anonymous reviewer.

\section{Author contributions}

EL and MC conceived and designed the study. EL performed the experiments/collected the data. EL, $\mathrm{MC}$, and SJ analyzed and interpreted the data. EL, MC, and SJ contributed resources. EL, MC, and SJ drafted or revised the manuscript.

\section{Competing interests}

SJ is currently serving as a Subject Editor for FACETS, but was not involved in review or editorial decisions regarding this manuscript.

\section{Data accessibility statement}

All relevant data are within the paper.

\section{References}

Barrie JV, and Currie RG. 2000. Human impact on the sedimentary regime of the Fraser River Delta, Canada. Journal of Coastal Research, 16: 747-755.

Behrenfeld MJ, and Falkowski PG. 1997. A consumer's guide to phytoplankton primary productivity models. Limnology and Oceanography, 42: 1479-1491. DOI: 10.4319/lo.1997.42.7.1479

Bergmann T, Fahnenstiel G, Lohrenz S, Millie D, and Schofield O. 2004. Impacts of a recurrent resuspension event and variable phytoplankton community composition on remote sensing reflectance. Journal of Geophysical Research: Oceans, 109: C10S15. DOI: 10.1029/2002JC001575

Boss E, Pegau WS, Lee M, Twardowski M, Shybanov E, Korotaev G, et al. 2004. Particulate backscattering ratio at LEO 15 and its use to study particle composition and distribution. Journal of Geophysical Research: Oceans, 109: C01014. DOI: 10.1029/2002JC001514

Bukata RP, Jerome JH, Kondratyev KY, and Pozdnyakov DV. 1995. Optical properties and remote sensing of inland and coastal waters. CRC Press, Boca Raton, Florida.

Collins AK. 2005. A 1D ocean mixing model of the Strait of Georgia: ecological responses to physical forcing. M.Sc. thesis, University of British Columbia, Vancouver, British Columbia. 144 p. 
Doxaran D, Cherukuru RCN, and Lavender SJ. 2004. Estimation of surface reflection effects on upwelling radiance field measurements in turbid waters. Journal of Optics A: Pure and Applied Optics, 6: 690-697. DOI: 10.1088/1464-4258/6/7/006

Harrison PJ, Fulton JD, Taylor FJR, and Parsons TR. 1983. Review of the biological oceanography of the Strait of Georgia: pelagic environment. Canadian Journal of Fisheries and Aquatic Sciences, 40: 1064-1094. DOI: 10.1139/f83-129

Harrison PJ, Clifford PJ, Cochlan WP, Yin K, St. John MA, Thompson PA, et al. 1991. Nutrient and plankton dynamics in the Fraser River plume, Strait of Georgia, British Columbia. Marine Ecology Progress Series, 70: 291-304. DOI: 10.3354/meps070291

Harrison PJ, Mackas DL, Frost BW, Macdonald RW, and Crecelius EA. 1994. An assessment of nutrients, plankton and some pollutants in the water column of Juan de Fuca Strait, Strait of Georgia, and Puget Sound, and their transboundary transport. In Review of the marine environment and biota of Strait of Georgia, Puget Sound, and Juan de Fuca Strait: Proceedings of the BC/ Washington Symposium on the Marine Environment, Vancouver, British Columbia, 13 and 14 January 1994. Edited by RCH Wilson, RJ Beamish, F Aitkens, and J Bell. Canadian Technical Report of Fisheries and Aquatic Sciences 1948. pp. 138-173. Available from publications.gc.ca/ collections/collection_2014/mpo-dfo/Fs97-6-1948-eng.pdf.

Jerlov NG. 1976. Marine optics. Elsevier Scientific Publishing Company, New York, New York.

Johannessen SC, Macdonald RW, and Paton DW. 2003. A sediment and organic carbon budget for the greater Strait of Georgia. Estuarine, Coastal and Shelf Science, 56: 845-860. DOI: 10.1016/ S0272-7714(02)00303-7

Johannessen SC, O’Brien MC, Denman KL, and Macdonald RW. 2005. Seasonal and spatial variations in the source and transport of sinking particles in the Strait of Georgia, British Columbia, Canada. Marine Geology, 216: 59-77. DOI: 10.1016/j.margeo.2005.01.004

Johannessen SC, Masson D, and Macdonald RW. 2006. Distribution and cycling of suspended particles inferred from transmissivity in the Strait of Georgia, Haro Strait and Juan de Fuca Strait. Atmosphere-Ocean, 44: 17-27. DOI: 10.3137/ao.440102

Kirk JTO. 1994. Light and photosynthesis in aquatic ecosystems. Cambridge University Press, Cambridge, UK.

Kostaschuk R. 2002. Flow and sediment dynamics in migrating salinity intrusions: Fraser River estuary, Canada. Estuaries, 25: 197-203. DOI: 10.1007/BF02691307

Kostaschuk RA, and Luternauer JL. 1989. The role of the salt-wedge in sediment resuspension and deposition: Fraser River Estuary, Canada. Journal of Coastal Research, 5: 93-101.

Kostaschuk RA, Stephan BA, and Luternauer JL. 1993. Suspended sediment concentration in a buoyant plume: Fraser River, Canada. Geo-Marine Letters, 13: 165-171. DOI: 10.1007/ BF01593190

Kostaschuk RA, Luternauer JL, Barrie JV, Leblond PH, and Von Deichmann LW. 1995. Sediment transport by tidal currents and implications for slope stability: Fraser River Delta, British Columbia. Canadian Journal of Earth Sciences, 32: 852-859. DOI: 10.1139/e95-071 
Li M, Gargett A, and Denman K. 2000. What determines seasonal and interannual variability of phytoplankton and zooplankton in strongly estuarine systems? Estuarine, Coastal and Shelf Science, 50: 467-488. DOI: 10.1006/ecss.2000.0593

Loos EA, and Costa M. 2010. Inherent optical properties and optical mass classification of the waters of the Strait of Georgia, British Columbia, Canada. Progress in Oceanography, 87: 144-156. DOI: $10.1016 /$ j.pocean.2010.09.004

Luternauer JL, Mosher DC, Clague JJ, and Atkins RJ. 1998. Sedimentary environments of the Fraser Delta. In Geology and natural hazards of the Fraser River Delta, British Columbia. Edited by JJ Clague, JL Luternauer, and DC Mosher. Geological Survey of Canada Bulletin 525. pp. 27-39.

Mackas DL, and Harrison PJ. 1997. Nitrogenous nutrient sources and sinks in the Juan de Fuca Strait/ Strait of Georgia/Puget Sound estuarine system: assessing the potential for eutrophication. Estuarine, Coastal and Shelf Science, 44: 1-21. DOI: 10.1006/ecss.1996.0110

Masson D. 2006. Seasonal water mass analysis for the Straits of Juan de Fuca and Georgia. Atmosphere-Ocean, 44: 1-15. DOI: 10.3137/ao.440101

Masson D, and Cummins PF. 2004. Observations and modeling of seasonal variability in the Straits of Georgia and Juan de Fuca. Journal of Marine Research, 62: 491-516. DOI: 10.1357/ 0022240041850075

McKee D, and Cunningham A. 2005. Evidence for wavelength dependence of the scattering phase function and its implication for modeling radiance transfer in shelf seas. Applied Optics, 44: 126135. PMID: 15662894 DOI: 10.1364/AO.44.000126

Milliman JD. 1980. Sedimentation in the Fraser River and its estuary, southwestern British Columbia (Canada). Estuarine and Coastal Marine Science, 10: 609-633. DOI: 10.1016/ S0302-3524(80)80092-2

Mobley CD. 1994. Light and water: radiative transfer in natural waters. Academic Press, Inc., San Diego, California.

Mobley CD. 1995. The optical properties of water. In Handbook of optics. Edited by M Bass. 2nd edition. McGraw-Hill, New York, New York. pp. 43.3-43.56.

Mobley CD. 1999. Estimation of the remote-sensing reflectance from above-surface measurements. Applied Optics, 38: 7442-7455. PMID: 18324298 DOI: 10.1364/AO.38.007442

Mobley CD. 2001. Radiative transfer in the ocean. In Encyclopedia of ocean sciences. Edited by SA Thorpe, KK Turekian, and JH Steele. Academic Press, San Diego, California. pp. 2321-2330.

Mobley CD. 2017. Measures of reflectance [online]: Available from oceanopticsbook.info/view/ radiative_transfer_theory/level_2/measures_of_reflectance.

Mobley CD, Chai F, Xiu P, and Sundman LK. 2015. Impact of improved light calculations on predicted phytoplankton growth and heating in an idealized upwelling-downwelling channel geometry. Journal of Geophysical Research: Oceans, 120: 875-892. DOI: 10.1002/2014JC010588 
Pawlowicz R, Allen S, Dower J, Lee R, Harris S, Halverson M, et al. 2003. STRATOGEM-the Strait of Georgia ecosystem project. In Proceedings of the 2003 Georgia Basin/Puget Sound Research Conference. Edited by TW Droscher and DA Fraser. Available from archives.eopugetsound.org/ conf/2003GBPS_ResearchConference/rc_files/citation.htm.

Pawlowicz R, Riche O, and Halverson M. 2007. The circulation and residence time of the Strait of Georgia using a simple mixing-box approach. Atmosphere-Ocean, 45: 173-193. DOI: 10.3137/ao.450401

Peña MA, Masson D, and Callendar W. 2016. Annual plankton dynamics in a coupled physicalbiological model of the Strait of Georgia, British Columbia. Progress in Oceanography, 146: 58-74. DOI: $10.1016 /$ j.pocean.2016.06.002

Pharo CH, and Barnes WC. 1976. Distribution of surficial sediments of the central and southern Strait of Georgia, British Columbia. Canadian Journal of Earth Sciences, 13: 684-696. DOI: 10.1139/e76-071

Pope RM, and Fry ES. 1997. Absorption spectrum (380-700 nm) of pure water. II. Integrating cavity measurements. Applied Optics, 36: 8710-8723. PMID: 18264420 DOI: 10.1364/AO.36.008710

Riche OGJ, and Pawlowicz R. 2014. Variability in a fjord-like coastal estuary I: quantifying the circulation using a formal multi-tracer inverse approach. Estuarine, Coastal and Shelf Science, 137: 1-13. DOI: $10.1016 /$ j.ecss.2013.11.018

St. John MA, and Pond S. 1992. Tidal plume generation around a promontory: effects on nutrient concentrations and primary productivity. Continental Shelf Research, 12: 339-354. DOI: 10.1016/ 0278-4343(92)90035-I

Stecko JRP, and Bendell-Young LI. 2000. Contrasting the geochemistry of suspended particulate matter and deposited sediments within an estuary. Applied Geochemistry, 15: 753-775. DOI: 10.1016/ S0883-2927(99)00090-6

Stockner JG, Cliff DD, and Shortreed KRS. 1979. Phytoplankton ecology of the Strait of Georgia, British Columbia. Journal of the Fisheries Research Board of Canada, 36: 657-666. DOI: 10.1139/ f79-095

Thomas DJ, and Grill EV. 1977. The effect of exchange reactions between Fraser River sediment and seawater on dissolved $\mathrm{Cu}$ and $\mathrm{Zn}$ concentrations in the Strait of Georgia. Estuarine and Coastal Marine Science, 5: 421-427. DOI: 10.1016/0302-3524(77)90066-4

Tully J, and Dodimead AJ. 1957. Properties of the water in the Strait of Georgia, British Columbia, and influencing factors. Journal of the Fisheries Research Board of Canada, 14: 241-319. DOI: 10.1139/f57-012

Twardowski MS, Boss E, Macdonald JB, Pegau WS, Barnard AH, and Zaneveld JRV. 2001. A model for estimating bulk refractive index from the optical backscattering ratio and the implications for understanding particle composition in case I and case II waters. Journal of Geophysical Research: Oceans, 106: 14129-14142. DOI: 10.1029/2000JC000404

Waldichuk M. 1957. Physical oceanography of the Strait of Georgia, British Columbia. Journal of the Fisheries Research Board of Canada, 14: 321-486. DOI: 10.1139/f57-013

Water Office. 2017. Daily discharge graph for Fraser River at Hope (08MF005) [online]: Available from wateroffice.ec.gc.ca/report/real_time_e.html?stn=08MF005. 
Yin KD, and Harrison PJ. 2000. Influences of flood and ebb tides on nutrient fluxes and chlorophyll on an intertidal flat. Marine Ecology Progress Series, 196: 75-85. DOI: 10.3354/meps196075

Yin KD, Harrison PJ, Pond S, and Beamish RJ. 1995. Entrainment of nitrate in the Fraser River estuary and its biological implications. II. Effects of spring vs. neap tides and river discharge. Estuarine, Coastal and Shelf Science, 40: 529-544. DOI: 10.1006/ecss.1995.0036

Yin KD, Harrison PJ, and Beamish RJ. 1997. Effects of a fluctuation in Fraser River discharge of primary production in the central Strait of Georgia, British Columbia, Canada. Canadian Journal of Fisheries and Aquatic Sciences, 54: 1015-1024. DOI: 10.1139/f97-010 